\title{
Farklı Arazi Kullanımlarının Toprakların Bazı Özellikleri ve Azot Mineralizasyonu Üzerindeki Etkisi (Rize, Kalkandere Örneği)
}

\author{
Mehmet KÜÇÜK ${ }^{1}$, İsmet YENER ${ }^{1 *}$ \\ ${ }^{1}$ Artvin Çoruh Üniversitesi, Orman Fakültesi, Orman Mühendisliği Bölümü, 08100, ARTVINN
}

\section{Öz}

$\mathrm{Bu}$ çalışmada arazi kullanım farklılığının toprakların bazı özellikleri ile azot mineralizasyonu üzerindeki etkilerinin belirlenmesi amaçlanmıştır. Bu çalışma kapsamında Rize, Kalkandere'de orman, çay, fındık ve kivi alanlarının her birinden 5 farklı noktada örnekleme yapılmıştır. Her örnekleme alanından birer toprak çukuru açılarak 0-15 cm ve $15-30 \mathrm{~cm}$ derinlik kademelerinden 40 'ar adet bozulmuş ve bozulmamış toprak örneği alınmıştır. Toprak örneklerinde tekstür, toprak reaksiyonu $(\mathrm{pH})$, organik karbon, toplam azot, karbon/azot oranı, elektriksel iletkenlik (EC), kireç $\left(\mathrm{CaCO}_{3}\right)$, hacim ağırlığ 1 ve azot mineralizasyonu gibi özellikler belirlenmiştir. Arazi kullanım durumuna göre toprak özelliklerindeki farklılığı belirlemek için nanparametrik Kruskal Wallis testi uygulanmıştır. Arazi kullanım durumuna ilişkin ikili karşılaştırmalarda ise Dunn's Bonferroni test uygulanmıștır. Analiz sonuçlarına göre $0-15 \mathrm{~cm}$ derinlik kademesinde kil, pH, organik karbon, elektriksel iletkenlik, hacim ağırlığ $, \mathrm{T}_{0} \mathrm{NO}_{3}, \mathrm{~T}_{0 \mathrm{NH}_{4}}+\mathrm{NO}_{3}, \mathrm{~T}_{63} \mathrm{NH}_{4}$ ve $\mathrm{T}_{63} \mathrm{NH}_{4}+\mathrm{NO}_{3}$ gibi toprak özellikleri anlaml şekilde farklılık gösterirken, 15-30 cm derinlik kademesinde bu özellikler kum, kil, pH, elektriksel iletkenlik, hacim ağırlığı, $\mathrm{T}_{63} \mathrm{NH}_{4}$ ve $\mathrm{T}_{63} \mathrm{NH}_{4}+\mathrm{NO}_{3}$ şeklinde ortaya çıkmıştır. Bu çalışmaya göre doğal orman alanları topraklarının diğer arazi kullanım durumu topraklarına göre anlamlı bir şekilde daha az kil $(p=0,008)$, EC ( $p=0,003)$, hacim ağırlığı $(\mathrm{p}=0,003), \mathrm{T}_{0} \mathrm{NO}_{3}(\mathrm{p}=0,006)$ ve $\mathrm{T}_{0} \mathrm{NH}_{4}+\mathrm{NO}_{3}(\mathrm{p}=0,005)$; daha fazla kum $(\mathrm{p}=0,006)$ ve $\mathrm{T}_{63} \mathrm{NH}_{4}+\mathrm{NO}_{3}$ $(\mathrm{p}=0,007)$ içerdiği belirlenmiştir.

Anahtar Kelimeler: Kruskal Wallis, Dunn’s Bonferroni, orman, çay bahçesi.

\section{Effect of Different Land Uses on Some Properties and N- Mineralization of The Soils (A case study from Rize, Kalkandere)}

\begin{abstract}
The aim of the present study was to investigate the effect of of land use change on some properties and $\mathrm{N}$ mineralization of the soils. For this purpose, 5-different point was sampled in each land use including natural forest, tea plantation, hazelnut and kiwi fields. Total 40 disturbed and 40 undisturbed soil samples were taken from 0-15 cm and 15-30 soil depth in each sample plot. The texture, $\mathrm{pH}$, electrical conductivity, $\mathrm{CaCO}_{3} \mathrm{content}_{\text {, }}$ bulk density, total nitrogen, $\mathrm{C} / \mathrm{N}$ ratio and $\mathrm{N}$-mineralization were determined on each soil sample. Nonparametric Kruskal Wallis test was carried out to determine differences in given soil properties according to land uses. Then Dunn's Bonferroni test was carried out for pairwise comparisons of the land-cover groups. As a result, while the clay content, $\mathrm{pH}$, organic carbon, EC, bulk density, $\mathrm{T}_{0} \mathrm{NO}_{3}, \mathrm{~T}_{0} \mathrm{NH}_{4}+\mathrm{NO}_{3}, \mathrm{~T}_{63} \mathrm{NH}_{4}$ and $\mathrm{T}_{63} \mathrm{NH}_{4}+\mathrm{NO}_{3}$ in 0-15 cm soil depth were significantly $(\mathrm{p}<0,05)$ affected by land use change; in 15-30 soil depth, sand and clay content, $\mathrm{pH}, \mathrm{EC}$, bulk density, $\mathrm{T}_{63} \mathrm{NH}_{4}$ and $\mathrm{T}_{63} \mathrm{NH}_{4}+\mathrm{NO}_{3}$ were affected. It was concluded that natural forests' soils have had significantly less clay content $(\mathrm{p}=0,008), \mathrm{EC}(\mathrm{p}=0,003)$, bulk density $(\mathrm{p}=0,003)$, $\mathrm{T}_{0} \mathrm{NO}_{3}(\mathrm{p}=0,006)$ and $\mathrm{T}_{0} \mathrm{NH}_{4}+\mathrm{NO}_{3}(\mathrm{p}=0,005)$; more sand content $(\mathrm{p}=0,006)$ and $\mathrm{T}_{63} \mathrm{NH}_{4}+\mathrm{NO}_{3}(\mathrm{p}=0,007)$ compared to the other land uses.
\end{abstract}

Keywords: Kruskal Wallis, Dunn's Bonferroni, forest, tea plantation.

\footnotetext{
*Sorumlu Yazar (Corresponding Author):

İsmet YENER (Dr.); Artvin Çoruh Üniversitesi, Orman Fakültesi, Orman

Mühendisliği Bölümü, 08100, Artvin-Türkiye. Tel: +90 (466) 215 1035, Fax: +90

Geliș (Received) : :01.07.2019

Kabul (Accepted) : 09.10.2019

Basım (Published) : 15.12.2019
} 


\section{Giriş}

Hızlı nüfus artışına bağlı olarak artan gıda, yerleşim yeri vb. ihtiyaçlarını karşılamak üzere doğal kaynaklar üzerinde yarattıkları olumsuz etkiler üzerine birçok çalışma yapılmıştır (Islam ve Weill, 2000; Wang, 2006; Korkanç vd., 2008; Özalp vd., 2016). Bu olumsuzluklardan etkilenen önemli doğal kaynaklardan biri de ormanlardır. Son 300 yılda dünyadaki orman alanlarının \%15 kadar azaldığı buna karşın tarım ve mera alanlarının ise \%371-611 arasında artış gösterdiği bildirilmektedir (Hartemink vd., 2008). Arazi kullanım sınıfları dikkate alınmadan ormanların tahrip edilerek tarım ve mera gibi arazi kullanımlarına dönüştürülmesiyle geri dönüşü çok zor bozulmalar gerçekleşmektedir (Hall vd., 2003; Lemeneh 2004; Oğuz ve Acar, 2011; Yihenew ve Getachew, 2013). Ormanların başka arazi kullanımlarına dönüştürülmesi ile biyoçeşitlilik, yaban hayatı, bazı toprak özellikleri, besin maddeleri ve su döngüsünde olumsuz değişimler olabilmektedir. Bu değişimler birçok araştırmacı (Karagül, 1999; Jackson vd., 2000; Germer vd., 2010; Agnese, 2011; Chakravarty vd., 2011; Gelaw vd., 2014) tarafından çalışılmıştır.

Arazi kullanım durumundaki değişimle birlikte özellikle organik madde, pH, bitki besin maddeleri ve azot mineralizasyonu gibi toprak özelliklerinde önemli değişiklikler meydana gelebilmektedir (Ross vd., 1999; Parfitt vd., 2003; Tecimen, 2011; Yihenew ve Getachew, 2013; Özalp vd., 2016). Toprakta bulunan azot, karasal ekosistemlerde bitki büyümesini ve net birincil üretimi etkileyen en önemli elementlerden birisidir (Wu vd., 2007; Elser vd., 2007). Azot, genellikle bitkiler tarafindan inorganik formda (NH4+-N ve NO3--N) alınmasına (Li vd., 2012) karşın topraktaki azotun \% 92-98' i organik formlarda bulunmaktadır. Azot mineralizasyonu, toprak organik azotunun inorganik forma dönüştürülmesinde, bitkiler tarafından alınabilir azot miktarını doğrudan etkilemektedir.(Song vd., 2013). Organik azotun mineralizasyonu amonifikasyon ve nitrifikasyon olmak üzere iki aşamada gerçekleşmektedir (Shi vd., 2014). Toprak mikroorganizmaları tarafından gerçekleştirilen azot mineralizasyonu sürecinde, organik maddeden inorganik formlara azot dönüşümü gerçekleşir. Azot mineralizasyonu mikrobiyal çeşitlik (Merilla vd., 2002) arazi kullanımı, toprağın fiziksel ve kimyasal özellikleri (Giardina vd. 2001), sıcaklık ve nem (Choromonska ve De Luca, 2002), bitki örtüsü (Ross vd., 2004; Templer vd., 2005), ölü örtü miktarı ve kalitesi (Berendse, 1990) gibi birçok faktör tarafindan etkilenebilmektedir.

$\mathrm{Bu}$ çalışmada, Rize ilinde arazi kullanım durumundaki değişimlerin, toprağın bazı fiziksel ve kimyasal özellikleri ile azot mineralizasyonu üzerindeki etkisinin belirlenmesi amaçlanmıştır.

\section{Materyal ve Metot}

\subsection{Materyal}

$\mathrm{Bu}$ çalışmanın materyalini alana ilişkin olarak elde edilen memleket ve meşcere haritaları, alanda iki derinlik kademesinden alınan toplam 40 adet bozulmuş (torba), 40 adet bozulmamış (silindir) örneği ile alanda yapılan bazı ölçüm ve gözlemler oluşturmaktadır.

\subsection{Araştırma Alanının Tanıtımı}

Araştırma alanı olarak, Rize ili Kalkandere ilçesi Hüseyinhoca köyü sınırları içinde kalan alanlar seçilmiştir (Şekil 1). Araştırma alanı yükseltisi ortalama $100 \mathrm{~m}$, bakısı güney batı yönündedir. Ortalama eğimi \% 45-50 arasındadır. Sahile uzaklığı yaklaşık olarak $10 \mathrm{~km}$ 'dir. Rize ili iklim özellikleri bakımından çok nemli iklim sınıfında yer almaktadır. Rize ilinin yıllık ortalama toplam yağışı 2240,7 mm, yıllık ortalama sıcaklığı ise $14,23{ }^{\circ} C^{\prime}$ dir (MGM, 2014). Sahilden iç kesimlere doğru gidildikçe yağış oranında bir azalma söz konusudur. Çalışma alanı olarak gürgen kestane karışık ormanı ile bitişiğindeki, kivi, çay ve findık tarımı yapılan alanlar seçilmiştir. Araştırma alanı kumlu balçık ve killi balçık tekstüründeki topraklardan oluşmaktadır.

Araştırma alanının da içinde yer aldığı Doğu Karadeniz bölgesi volkanik bir alandan oluşmaktadır. Üst Kretase'de oluşan dasit, bazalt ve tortul birimler kendini göstermekte olup buralarda bazalt egemen durumdadır. Üst Kretase volkanitleri üzerine ise uyumsuz olarak Eosen yaşlı volkanik oluşumlar gelmiştir. Bunlar daha çok aralarında ince tabakalı tortullar da içeren bazalt ve andezitlerdir (Özçağlar vd., 2006).

\subsection{Toprak Örneklerinin Alınması}

Bu çalışma 2013 yılında yapılmış olup örnekler katmanlı rastgele örnekleme yöntemi kullanılarak alınmıştır (Pennock vd., 2007). Bu amaçla, 4 farklı arazi kullanım sınıfındaki (orman, fındık, kivi ve çay bahçesi) birinci derinlik $(0-15 \mathrm{~cm})$ ve ikinci derinlik $(15-30 \mathrm{~cm})$ kademelerindeki topraklardan 20'şer adet olmak üzere 
toplam 40 adet bozulmuş (torba) ve 40 adet de bozulmamış (silindir) toprak örneği alınmıştır.

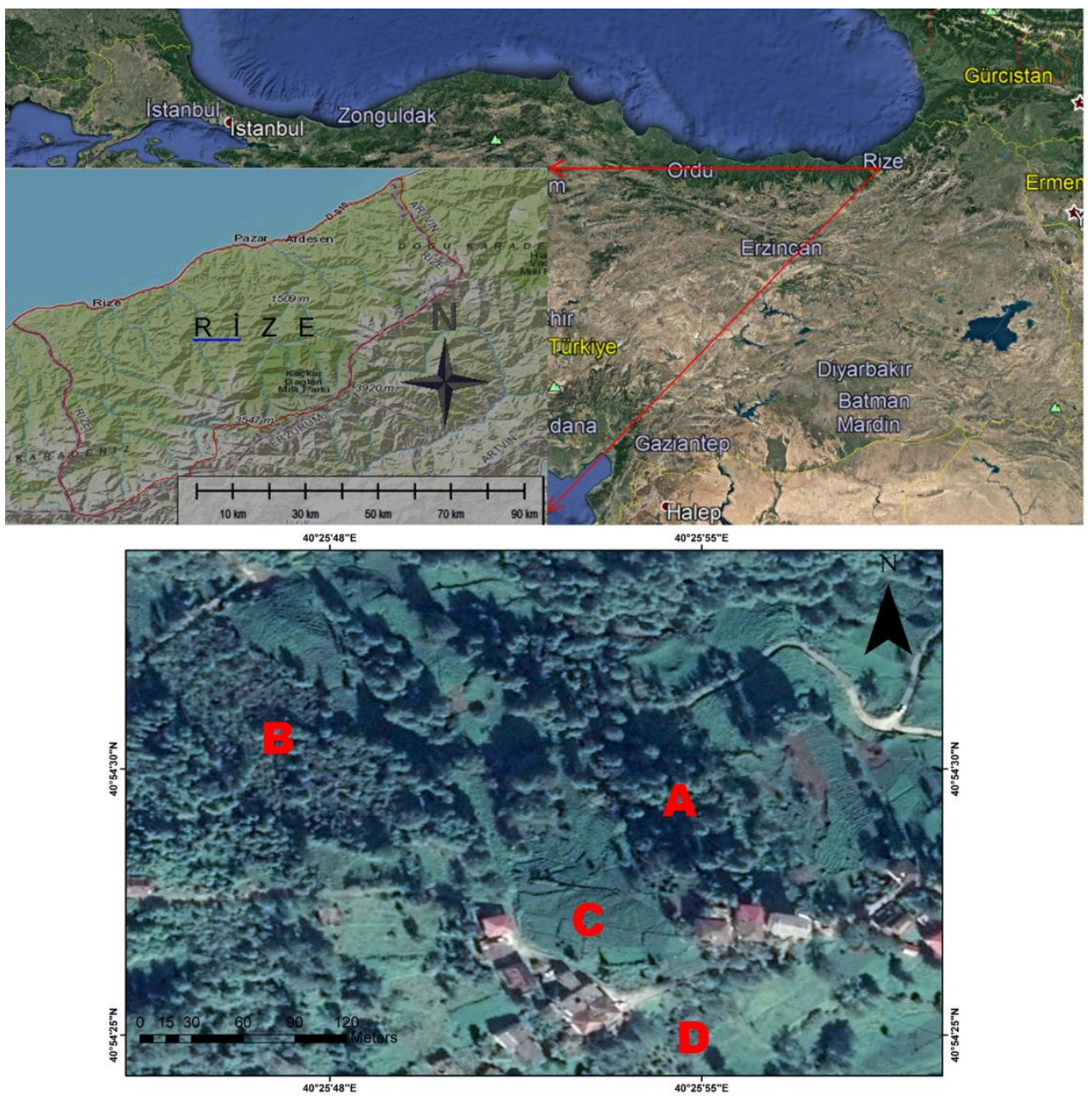

Şekil 1. Araştırma alanının konumu (A: Orman, B: Fındık, C: Çay, D: Kivi).

\subsection{Laboratuvar ve İstatistik Yöntemler}

Alınan toprak örnekleri hava kurusu hale gelinceye kadar kurutulup ögütülerek 2 mm'lik elekten geçirilmiş ve analize hazır hale getirilmiştir. Toprak tekstürü Bouyoucos'un hidrometre yöntemine göre (Boyoucos, 1962), hacim ağırlığı ise çelik silindirle alınan toprak örnekleri $105^{\circ} \mathrm{C}^{\prime} l i k$ sıcaklıkta firın kurusu hale getirildikten sonra Blake ve Hartge'ye (1986) göre belirlenmiştir. pH ve EC, 1:2,5 toprak-su karışımında cam elektrot yöntemi ile (Gülçur, 1974) belirlenirken organik karbon, değiştirilmiş Walkley-Black 1slak yakma yöntemi ile (Walkley, 1947) belirlenmiştir. Toprakların kireç içeriği Scheibler kalsimetresinde (Nelson, 1982), toplam azot Kjheldal destilasyon ve titrasyon yöntemi (Pansu ve Gautheyrou, 2007) ve azot mineralizasyonu mikrodestilasyon yöntemine göre (Bremner and Keeney 1965) $25{ }^{\circ} \mathrm{C}$ s1caklıkta \%60 toprak nemine sahip laboratuvar koşullarında 63 günlük bekleme süresi ile belirlenmiştir. Net mineralizasyon ise başlangıç ve 63 günlük mineralizasyon arasındaki farktan yararlanılarak hesaplanmıştır.

Verilerin değerlendirilmesinde SPSS 20.0 paket programı kullanılmıştır (IBM.Corp., 2011). Toprak özelliklerinde arazi kullanım durumuna bağlı olarak bir farklılık olup olmadığını belirlemek amacıyla ANOVA'nın parametrik olmayan karşılığı olan Kruskal-Wallis testi kullanılmıştır (Leech vd., 2005). Grupların ikili karşılaştırmasında ise Bonferroni düzeltmesi yapılarak Dunn’s Bonferrroni test kullanılmıştır (Dunn, 1964; URL 1). Bu düzeltme sonucunda ikili karşılaştırmalardaki anlamlılık düzeyi (p) 0,05 değil bunun karşılaştırılan grup sayısı olan 6'ya bölünmesi sonucu bulunan 0,0083 olarak alınmıştır. Parametrik olmayan istatistik yöntem kullanıldığı için bulgular ve tartışma bölümlerindeki değerlendirmeler aritmetik ortalamalar yerine medyanlar üzerinden yapılmıştır. 


\section{Bulgular ve Tartışma}

\subsection{Fiziksel Toprak Özellikleri}

\section{Tekstür}

Arazi kullanım durumuna göre toprakların kum, kil ve toz içerikleri Tablo 1'de verilmiştir. Kruskal-Wallis test sonuçlarına göre kil içeriği bakımından birinci ve ikinci derinlik kademelerinde sırasıyla $p=0,013$ ve $p=0,016$ ve kum içeriği bakımından ikinci derinlik kademesinde $\mathrm{p}=0,006$ önem düzeyinde anlamlı farklılıklar bulunmuştur (Tablo 2). İkili karşılaştırmalara bakıldığında arazi kullanım durumuna göre kum içeriği bakımından birinci derinlik kademesinde herhangi anlamlı bir farklılık bulunamamıștır. İkinci derinlik kademesinde orman alanlarındaki kum içeriği $(\% 77,5)$ fındık $(\% 46,7)$ ve çaya $(\% 54,9)$ göre anlamlı bir şekilde daha yüksek bulunmuştur (Şekil 2e). Orman alanlarındaki kil içeriği $(\% 9,6)$ fındık bahçelerine göre hem birinci derinlik kademesinde $(\% 21,9)$ hem de ikinci derinlik kademesinde $(\% 32,1)$ anlamlı bir şekilde daha düşük bulunmuştur (Şekil 2a, 2c). Toz içeriği bakımından ise arazi kullanımları arasında anlamlı bir farklılık bulunamamıştır.

Orman alanlarından tarım alanlarına geçişte genel olarak kum içeriğinde bir azalma kil içeriğinde ise bir artış tespit edilmiştir. Tarım topraklarındaki kil içeriğinin daha yüksek olması hem kullanılan azotlu gübreler nedeniyle toprakta meydana gelen kimyasal bozulmaya hem de toprak işlemeye bağlanabilir (Erol ve Hızal 2006; Yener vd., 2017). Benzer sonuçlar diğer bazı araştırmacılar (Patel vd., 2010; Küçük, 2013; Bardak, 2016) tarafindan da bulunmuştur.

\section{Hacim Ağırlığı}

Arazi kullanım durumuna göre toprakların hacim ağırlığı (HA) değerleri Tablo 1'de verilmiştir. Kruskal Wallis'e göre HA bakımından birinci ve ikinci derinlik kademelerinde sırasıyla $p=0,005$ ve $p=0,001$ önem düzeylerinde anlamlı farklılıklar belirlenmiştir (Tablo 2). Birinci derinlik kademesinde findık alanlarındaki HA $\left(0,95 \mathrm{~g} / \mathrm{cm}^{3}\right)$ orman alanlarına $\left(0,45 \mathrm{~g} / \mathrm{cm}^{3}\right)$; ikinci derinlik kademesindeki HA $\left(1,035 \mathrm{~g} / \mathrm{cm}^{3}\right)$ ise kivi alanlarına $(\% 0,59)$ göre anlamlı bir şekilde daha yüksek bulunmuştur (Şekil 2b, 2d). Orman alanlarındaki HA’nın daha düşük olması daha fazla organik madde içermesine bağlanabilir. Tarım alanlarındaki yoğun toprak işleme sonucunda organik madde içeriği azalıp toprak strüktürü bozulurken insan trafiği ile de toprakların infiltrasyon kapasitesinin düşmesine bağlı olarak yüzeysel akış ve erozyon artmaktadır (Weil ve Brady, 2016). Benzer sonuçlar diğer bazı araştırmacılar (Assefa vd., 2017; Gol, 2017; Özalp vd., 2016; Toohey et al., 2018) tarafindan da bulunmuştur.

Tablo 1. Bazı fiziksel toprak özelliklerinin arazi kullanım durumuna göre karşılaştırılması.

\begin{tabular}{llllllllll}
\hline & \multicolumn{9}{c}{$\mathbf{0 - 1 5} \mathbf{~ c m}$} \\
\cline { 2 - 9 } & & \multicolumn{1}{c}{ Çay } & Findık & \multicolumn{1}{c}{ Kivi } & Orman & Çay & \multicolumn{1}{c}{ Findık } & \multicolumn{1}{c}{ Kivi } & Orman \\
\cline { 2 - 9 } Kum & $\mathbf{x} \pm$ SE & $58,6 \pm 3,5$ & $61,1 \pm 4,7$ & $70,1 \pm 5,5$ & $68,9 \pm 5,8$ & $54,1 \pm 3,5$ & $47,9 \pm 6,8$ & $64,8 \pm 4,1$ & $76,7 \pm 1,5$ \\
& $\mathbf{M}$ & $56,95 \mathrm{a}$ & $67,24 \mathrm{a}$ & $75,47 \mathrm{a}$ & $75,47 \mathrm{a}$ & $54,9 \mathrm{a}$ & $46,67 \mathrm{a}$ & $67,24 \mathrm{ab}$ & $77,53 \mathrm{~b}$ \\
Kil & $\overline{\mathbf{x}} \pm$ SE & $21,5 \pm 3,8$ & $24,4 \pm 2,0$ & $12,0 \pm 0,8$ & $12,4 \pm 3,5$ & $24,8 \pm 4,6$ & $30,9 \pm 5,8$ & $18,6 \pm 0,8$ & $10,0 \pm 1,4$ \\
& $\mathbf{M}$ & $17,78 \mathrm{ab}$ & $21,89 \mathrm{a}$ & $11,61 \mathrm{ab}$ & $9,55 \mathrm{~b}$ & $19,84 \mathrm{ab}$ & $32,18 \mathrm{a}$ & $19,84 \mathrm{ab}$ & $9,55 \mathrm{~b}$ \\
Toz & $\overline{\mathbf{x}} \pm$ SE & $19,9 \pm 3,6$ & $14,6 \pm 2,9$ & $17,9 \pm 5,6$ & $18,7 \pm 4,0$ & $21,2 \pm 1,5$ & $21,2 \pm 1,6$ & $16,6 \pm 4,1$ & $13,3 \pm 1,2$ \\
& $\mathbf{M}$ & $17,04 \mathrm{a}$ & $12,92 \mathrm{a}$ & $10,86 \mathrm{a}$ & $12,92 \mathrm{a}$ & $21,15 \mathrm{a}$ & $19,1 \mathrm{a}$ & $12,92 \mathrm{a}$ & $12,92 \mathrm{a}$ \\
HA & $\overline{\mathbf{x}} \pm$ SE & $0,9 \pm 0,0$ & $1,0 \pm 0,1$ & $0,6 \pm 0,0$ & $0,6 \pm 0,1$ & $0,9 \pm 0,0$ & $1,1 \pm 0,0$ & $0,6 \pm 0,0$ & $0,9 \pm 0,0$ \\
& $\mathbf{M}$ & $0,911 \mathrm{ab}$ & $0,95 \mathrm{a}$ & $0,594 \mathrm{ab}$ & $0,454 \mathrm{~b}$ & $0,926 \mathrm{ab}$ & $1,035 \mathrm{a}$ & $0,586 \mathrm{~b}$ & $0,965 \mathrm{ab}$ \\
\hline
\end{tabular}

* $\overline{\mathrm{x}} \pm$ SE: Aritmetik ortalama \pm standart hata, M: Medyan, HA: Hacim ağırlığ 1 

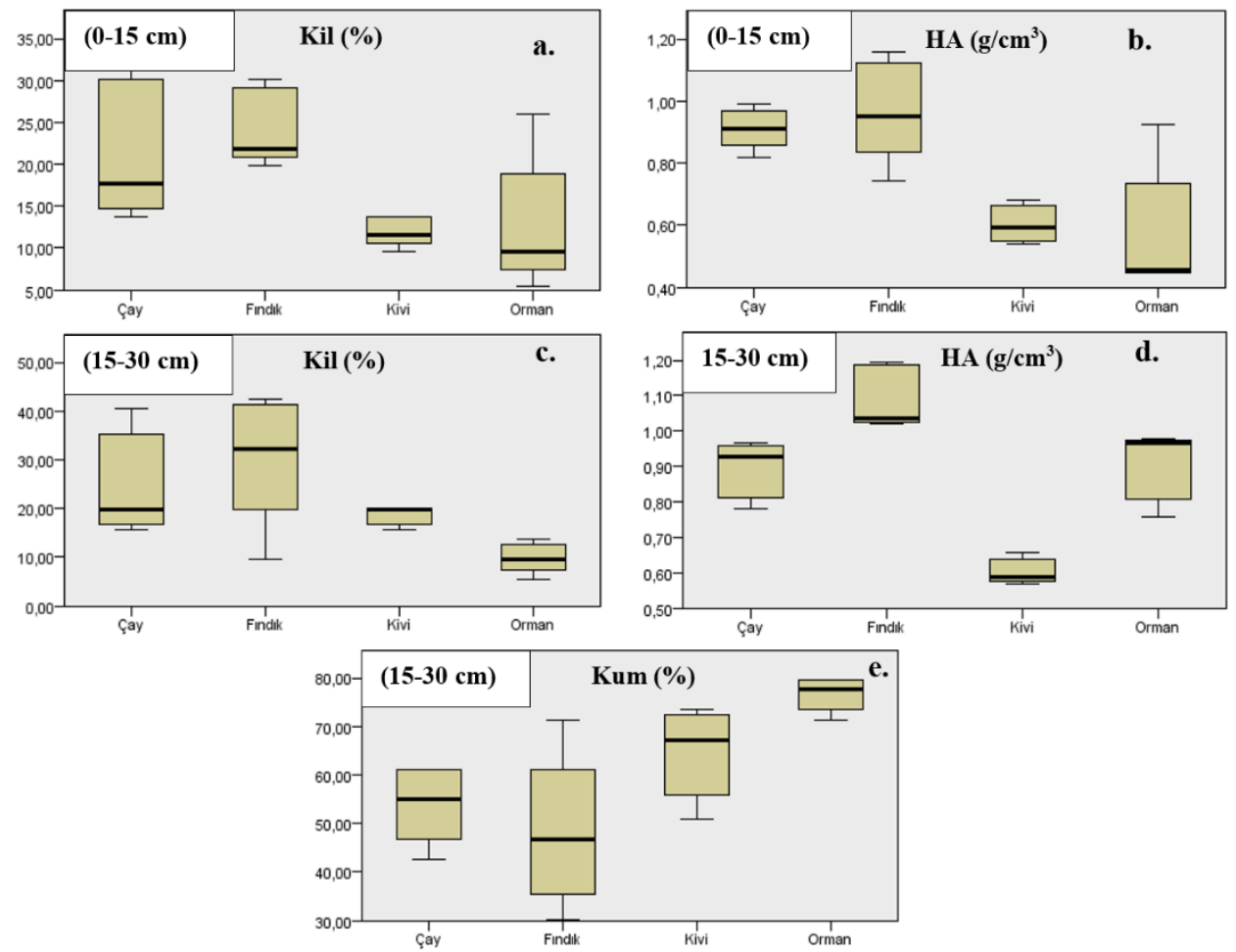

Şekil 2. Arazi kullanım durumuna göre anlamlı farklılık gösteren bazı fiziksel toprak özelliklerinin değişimi.

Tablo 2. Kruskal Wallis testi sonucunda arazi kullanımlarına göre farklı bulunan toprak özelliklerinde Dunn's Bonferroni testine göre ikili karşılaştırmalar.

\begin{tabular}{|c|c|c|c|c|c|c|c|}
\hline \multicolumn{4}{|c|}{ 0-15 cm Toprak Derinliği } & \multicolumn{4}{|c|}{ 15-30 cm Toprak Derinliği } \\
\hline $\begin{array}{c}\text { Bağımlı } \\
\text { Değişsken }\end{array}$ & $\begin{array}{c}\text { Kruskal- } \\
\text { Wallis } \\
\text { (p) }\end{array}$ & $\begin{array}{c}\text { İkili } \\
\text { Karşılaştırma }\end{array}$ & $\begin{array}{c}\text { Dunn's } \\
\text { Bonferroni } \\
\text { (p) }\end{array}$ & $\begin{array}{c}\text { Bağımlı } \\
\text { Değişken }\end{array}$ & $\begin{array}{c}\text { Kruskal- } \\
\text { Wallis } \\
\text { (p) }\end{array}$ & $\begin{array}{c}\text { İkili } \\
\text { Karşılaştırma }\end{array}$ & $\begin{array}{c}\text { Dunn's } \\
\text { Bonferroni } \\
\text { (p) }\end{array}$ \\
\hline Kil & 0,013 & $\mathrm{O}-\mathrm{F}$ & 0,008 & Kum & 0,006 & $\mathrm{~F}-\mathrm{O}$ & 0,001 \\
\hline pH & 0,004 & $\mathrm{C}-\mathrm{F}$ & 0,002 & & & $\mathrm{C}-\mathrm{O}$ & 0,006 \\
\hline OM & 0,017 & $\mathrm{C}-\mathrm{O}$ & 0,004 & Kil & 0,016 & $\mathrm{O}-\mathrm{F}$ & 0,003 \\
\hline EC & 0,015 & $\mathrm{O}-\mathrm{F}$ & 0,003 & $\mathbf{p H}$ & 0,002 & $\mathrm{O}-\mathrm{F}$ & 0,001 \\
\hline HA & 0,005 & $\mathrm{O}-\mathrm{F}$ & 0,003 & & & $\mathrm{C}-\mathrm{F}$ & 0,005 \\
\hline $\mathrm{T}_{0} \mathrm{NO}_{3}$ & 0,025 & $\mathrm{O}-\mathrm{C}$ & 0,006 & EC & 0,025 & $\mathrm{O}-\mathrm{C}$ & 0,006 \\
\hline $\mathrm{T}_{0} \mathrm{NO}_{3}+$ & 0,015 & $\mathrm{O}-\mathrm{C}$ & 0,005 & HA & 0,001 & $\mathrm{~K}-\mathrm{F}$ & 0,000 \\
\hline $\mathbf{N H}_{4}$ & & $\mathrm{O}-\mathrm{F}$ & 0,005 & $\mathbf{T}_{0} \mathbf{N H}_{4}$ & 0,005 & $\mathrm{~K}-\mathrm{F}$ & 0,000 \\
\hline $\mathbf{N H}_{4}$ & 0,008 & $\mathrm{~K}-\mathrm{O}$ & 0,001 & $\mathrm{~T}_{63} \mathrm{NO}_{3}+$ & 0,011 & $\mathrm{~K}-\mathrm{O}$ & 0,007 \\
\hline $\mathrm{T}_{63} \mathrm{NO}_{3}+$ & 0,005 & $\mathrm{~K}-\mathrm{O}$ & 0,005 & $\mathbf{N H}_{4}$ & & $\mathrm{~K}-\mathrm{F}$ & 0,003 \\
\hline $\mathbf{N H}_{4}$ & & $\mathrm{~K}-\mathrm{F}$ & 0,001 & & & & \\
\hline
\end{tabular}

* OM: Organik madde, EC: Elektriksel iletkenlik, HA: Hacim ağırlığı

$\mathrm{T}_{0}$ : Başlangıçtaki azot mineralizasyonu, $\mathrm{T}_{63}: 63$ günlük azot mineralizasyonu

O: Orman, F: Fındık, Ç: Çay, K: Kivi

\subsection{Kimyasal Toprak Özellikleri}

\section{pH}

pH değerleri birinci ve ikinci derinlik kademelerinde çay topraklarında sırasıyla 3,9 ve 4,72 findık topraklarında 6,59 ve 6,99 kivi topraklarında 5,61 ve 5,60 ve orman topraklarında ise 4,37 ve 4,31 olarak belirlenmiştir (Tablo 3). Bu değerlere göre çay toprakları çok kuvvetli-kuvvetli asit, findık toprakları zayıf asit, kivi toprakları orta derecede asit ve orman toprakları ise kuvvetli asit topraklar sınıfında yer almıştır. Kruskal Wallis'e göre birinci ve ikinci derinlik kademelerinde sırasıyla $p=0,004$ ve $p=0,002$ önem düzeylerinde farklılıklar belirlenmiştir (Tablo 2). İkili karşılaştırmalarda, birinci derinlik kademesinde çay topraklarındaki pH fındık topraklarındakine göre $\mathrm{p}=0,002$ önem düzeyinde daha düşük; ikinci derinlik kademesinde ise çay ve orman topraklarındaki $\mathrm{pH}$ fındık topraklarına göre sırasıyla $p=0,001$ ve $p=0,005$ önem düzeylerinde daha düşük olarak belirlenmiştir 
(Şekil 3a, 3d). Çay topraklarındaki düşük pH uzun süreli gübrelemeler (hayvan gübresi, amonyum sülfat ve üre gibi) sonucunda topraktaki $\mathrm{H}^{+}$ve $\mathrm{Al}^{+3}$ konsantrasyonlarında artış, bazik katyonların $\left(\mathrm{Ca}^{++}\right.$ve $\mathrm{Mg}^{++}$gibi) konsantrasyonundaki düşüş ve çay bitkisinin yaprak ve diğer organlarındaki alüminyum depolanması ile ilişkilendirilebilir (Dang, 2002; Weil ve Brady, 2017). Benzer sonuçlar Bahrami vd. (2010) ve Yener vd. (2017) tarafından da belirlenmiştir. Bahrami vd. (2010) bu değişimi yoğun azot gübrelemesi ve çay plantasyonundan toprağa karışan atıklara bağlamıştır.

Tablo 3. Toprağın bazı kimyasal toprak özelliklerinin arazi kullanım durumuna göre karşılaştırılması.

\begin{tabular}{|c|c|c|c|c|c|c|c|c|c|}
\hline & & \multicolumn{4}{|c|}{$0-15 \mathrm{~cm}$} & \multicolumn{4}{|c|}{$15-30 \mathrm{~cm}$} \\
\hline & & Çay & Fındık & Kivi & Orman & Çay & Findık & Kivi & Orman \\
\hline \multirow[t]{2}{*}{ pH } & $\overline{\mathbf{x}} \pm \mathbf{S E}$ & $4,1 \pm 0,2$ & $6,1 \pm 0,5$ & $5,5 \pm 0,2$ & $4,5 \pm 0,1$ & $4,5 \pm 0,2$ & $6,5 \pm 0,4$ & $5,4 \pm 0,2$ & $4,2 \pm 0,1$ \\
\hline & $\mathbf{M}$ & $3,9 \mathrm{a}$ & $6,59 \mathrm{~b}$ & $5,61 \mathrm{ab}$ & $4,37 \mathrm{ab}$ & $4,72 \mathrm{a}$ & $6,99 b$ & $5,60 \mathrm{ab}$ & $4,31 \mathrm{a}$ \\
\hline \multirow{2}{*}{ OM } & $\overline{\mathbf{x}} \pm \mathbf{S E}$ & $4,1 \pm 0,6$ & $4,3 \pm 0,6$ & $5,9 \pm 0,8$ & $7,4 \pm 0,6$ & $3,5 \pm 0,2$ & $3,2 \pm 0,5$ & $4,3 \pm 0,8$ & $5,9 \pm 0,9$ \\
\hline & $\mathbf{M}$ & $4,66 \mathrm{a}$ & 4,63ab & $5,14 \mathrm{ab}$ & $8,26 \mathrm{~b}$ & $3,58 \mathrm{a}$ & $3,43 \mathrm{a}$ & $4,99 \mathrm{a}$ & $6,54 a$ \\
\hline \multirow{2}{*}{$\mathbf{T N}$} & $\overline{\mathbf{x}} \pm \mathbf{S E}$ & $0,2 \pm 0,0$ & $0,2 \pm 0,0$ & $0,2 \pm 0,0$ & $0,2 \pm 0,0$ & $0,2 \pm 0,0$ & $0,1 \pm 0,0$ & $0,1 \pm 0,0$ & $0,2 \pm 0,0$ \\
\hline & $\mathbf{M}$ & $0,19 \mathrm{a}$ & $0,16 \mathrm{a}$ & $0,16 \mathrm{a}$ & $0,24 \mathrm{a}$ & $0,19 \mathrm{a}$ & $0,11 \mathrm{a}$ & $0,15 \mathrm{a}$ & $0,185 \mathrm{a}$ \\
\hline \multirow{2}{*}{$\mathrm{C} / \mathrm{N}$} & $\overline{\mathbf{x}} \pm \mathbf{S E}$ & $14,3 \pm 3,3$ & $14,0 \pm 2,5$ & $21,1 \pm 2,1$ & $17,8 \pm 1,5$ & $10,2 \pm 1,4$ & $17,3 \pm 4,0$ & $16,5 \pm 3,0$ & $22,6 \pm 3,6$ \\
\hline & $\mathbf{M}$ & $13,06 a$ & $13,11 \mathrm{a}$ & $23,5 \mathrm{a}$ & $20,14 \mathrm{a}$ & $11,1 \mathrm{a}$ & $22,72 \mathrm{a}$ & $17,42 \mathrm{a}$ & $20,185 a$ \\
\hline \multirow{2}{*}{ EC } & $\overline{\mathbf{x}} \pm \mathbf{S E}$ & $254,4 \pm 9,9$ & $434,7 \pm 96,4$ & $254,7 \pm 50,3$ & $51,9 \pm 10,7$ & $289,0 \pm 37,4$ & $313,8 \pm 86,2$ & $229,6 \pm 38,4$ & $34,9 \pm 1,4$ \\
\hline & $\mathbf{M}$ & $251,9 \mathrm{ab}$ & $418 \mathrm{a}$ & $298,3 \mathrm{ab}$ & $39,7 \mathrm{~b}$ & $257,9 \mathrm{a}$ & $292,1 \mathrm{ab}$ & $243,3 \mathrm{ab}$ & $35,1 \mathrm{~b}$ \\
\hline \multirow{2}{*}{ Kireç } & $\overline{\mathbf{x}} \pm \mathbf{S E}$ & $0,9 \pm 0,2$ & $1,1 \pm 0,3$ & $0,5 \pm 0,0$ & $0,5 \pm 0,1$ & $1,3 \pm 0,3$ & $1,3 \pm 0,2$ & $0,7 \pm 0,2$ & $0,7 \pm 0,1$ \\
\hline & $\mathbf{M}$ & $0,8 \mathrm{a}$ & $1,07 \mathrm{a}$ & $0,52 \mathrm{a}$ & $0,52 \mathrm{a}$ & $1,45 \mathrm{a}$ & $1,09 \mathrm{a}$ & $0,75 \mathrm{a}$ & $0,705 \mathrm{a}$ \\
\hline
\end{tabular}

$* \overline{\mathrm{X}} \pm$ SE: Aritmetik ortalama \pm standart hata, M: Medyan

OM: Organik madde, TN: Toplam azot, C/N: Karbon: azot oran1, EC: Elektriksel iletkenlik

\section{Elektriksel İletkenlik}

Elektriksel iletkenlik (EC) değerleri, birinci ve ikinci derinlik kademelerinde, çay topraklarında sırasıyla 251,9 $\mu \mathrm{S} / \mathrm{cm}$ ve $257,9 \mu \mathrm{S} / \mathrm{cm}$, findık topraklarında $418 \mu \mathrm{S} / \mathrm{cm}$ ve $292,1 \mu \mathrm{S} / \mathrm{cm}$, kivi topraklarında $298,3 \mu \mathrm{S} / \mathrm{cm}$ ve $243,3 \mu \mathrm{S} / \mathrm{cm}$, ve orman topraklarında ise $39,7 \mu \mathrm{S} / \mathrm{cm}$ ve $35,1 \mu \mathrm{S} / \mathrm{cm}$ olarak belirlenmiştir (Tablo 3). Bu değerlere göre araştırma alanı toprakları tüm arazi kullanım durumları için tuzsuz topraklar sınıfında yer almıştır.

Kruskal Wallis test sonuçlarına göre EC birinci ve ikinci derinlik kademelerinde arazi kullanım durumları bakımından sırasıyla $\mathrm{p}=0,015$ ve $\mathrm{p}=0,025$ önem düzeylerinde farklı bulunmuştur (Tablo 2). İkili karşılaştırmalarda ise, birinci derinlik kademesinde orman topraklarındaki EC fındık topraklarına göre, ikinci derinlik kademesinde ise çay topraklarına göre daha düşük bulunmuştur (Şekil 3b, 3e). Orman topraklarındaki daha düşük EC suda çözünmüş tuzların daha az olmasını ifade etmektedir. Toprakta kil içeriği ve nitrat bileşiklerinin artışına bağlı olarak elektriksel iletkenlik artmaktadır (URL-2). Bu çalışmada birinci derinlik kademesinde findık, ikinci derinlik kademesinde ise çay alanlarındaki EC'nin orman alanlarındakinden daha yüksek olması bu alanlardaki kil içeriğinin, sırasıyla \%21,89 ve \%21,15, orman alanlarındaki kil içeriğinden, sırasıyla \%9,55 ve \%12,92, fazla olmasıyla açıklanabilir (Tablo 1). Öte yandan orman topraklarındaki drenajın, insan baskısı altında kalan, tarım topraklarına göre daha iyi olması ise diğer nedenlerdendir (Weil and Brady, 2017). Benzer sonuçlar diğer bazı araştırmacılar (Kara ve Bolat, 2008, Oğuz ve Acar 2011) tarafından da bulunmuştur.

\section{Kireç İçeriği}

Arazi kullanım durumlarına göre kireç içerikleri (CaCO3) birinci ve ikinci derinlik kademelerinde çay topraklarında sirasıyla $\% 0,8$ ve $\% 1,45$, findik topraklarında $\% 1,07$ ve $\% 1,09$, kivi topraklarında $\% 0,52$ ve $\% 0,75$ ve orman topraklarında ise $\% 0,52$ ve $\% 0,71$ olarak bulunmuştur (Tablo 3 ).

Kruskal Wallis testi sonuçlarına göre topraklardaki CaCO3 içeriği arazi kullanım durumuna göre anlamlı bir farkl1lık göstermemiştir. 

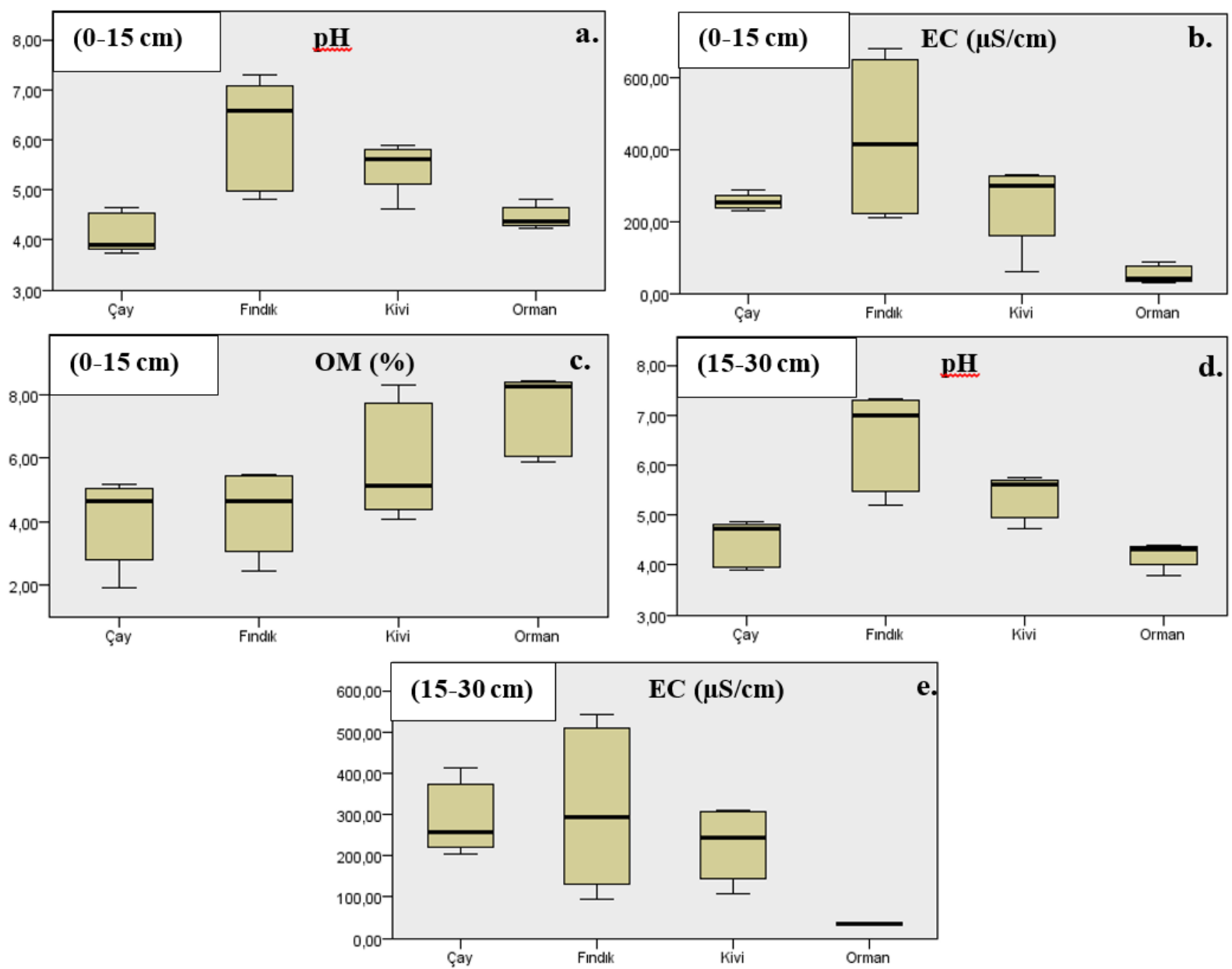

Şekil 3. Arazi kullanım durumuna göre anlamlı farklılık gösteren bazı kimyasal toprak özelliklerinin değişimi.

\section{Organik Madde}

Araştırma alanındaki organik madde (OM) içerikleri birinci ve ikinci derinlik kademelerinde, çay topraklarında sirasıyla $\% 4,66$ ve $\% 3,58$, findık topraklarında $\% 4,63$ ve $\% 3,43$, kivi topraklarında $\% 5,14$ ve $\% 4,19$, ve orman topraklarında ise \%8,26 ve \%6,54 olarak belirlenmiştir (Tablo 3). Bu OM içeriklerine göre çay, findık ve kivi toprakları yüksek OM sınıfında yer alırken orman toprakları çok yüksek OM sınıfında yer almıştır.

Kruskal Wallis testi sonuçlarına göre OM içerikleri açısından arazi kullanım durumları arasında sadece birinci derinlik kademesinde $p=0,017$ önem düzeyinde farklılık bulunurken ikinci derinlik kademesinde önemli bir farklılık bulunamamıştır (Tablo 2). İkili karşılaştırmalarda orman topraklarındaki OM içeriği çay topraklarına göre $\mathrm{p}=0,004$ önem düzeyinde daha yüksek bulunmuştur (Şekil 3c). Orman topraklarındaki OM içeriğinin çay topraklarına göre daha yüksek olması yoğun orman ölü örtüsüne sahip olması; çay topraklarındaki daha düşük OM ise sürekli yapılan toprak işleme ve hasat ile açıklanabilir (Kramer ve Green, 2000, Chen vd., 2003, Kara ve Bolat 2008, Weil ve Brady, 2017).

\section{Toplam Azot}

Araştırma alanındaki toplam azot (TN) içerikleri birinci ve ikinci derinlik kademelerinde çay topraklarında sirasıyla $\% 0,19$ ve $\% 0,19$, findık topraklarında $\% 0,16$ ve $\% 0,11$, kivi topraklarında $\% 0,16$ ve $\% 0,15$ ve orman topraklarında ise \%0,24 ve \%0,19 olarak belirlenmiştir (Tablo 3). Araştırma alanında birinci derinlik kademesindeki tüm arazi kullanımlarına ilişkin topraklar orta derecede TN içeren sınıfta yer alırken, ikinci derinlik kademesinde fındık alanlarında düşük diğer alanlarda ise orta derecede TN içeren sınıfta yer almışlardır.

Yapılan Kruskal Wallis testine göre TN değerleri arazi kullanım durumlarına göre farklılık göstermemiştir.

\section{Karbon/Azot Oranı}

Araştırma alanındaki karbon /azot oranı (C:N) birinci ve ikinci derinlik kademelerinde sırasıyla çay topraklarında 13,1 ve 11,1 , findık topraklarında 13,1 ve 22,7 , kivi topraklarında 23,5 ve 17,4 ve orman 
topraklarında ise 20,1 ve 20,2 olarak belirlenmiştir (Tablo 3). C:N değerleri dikkate alındığında araştırma alanı topraklarında ayrışma bakımından bir sorun olmadığı söylenebilir.

Kruskal Wallis testi sonuçlarına göre C:N oranı arazi kullanım durumuna bağlı olarak anlamlı bir şekilde değişmemiştir.

\subsection{Azot Mineralizasyonu}

Azot mineralizasyonu ölçümleri başlangıç ve 63 günlük olmak üzere 2 zaman diliminde incelenmiştir. Yine bu inceleme amonyum $\left(\mathrm{NH}_{4}\right)$, nitrat $\left(\mathrm{NO}_{3}\right)$, ve toplam mineralizasyon $\left(\mathrm{NH}_{4}+\mathrm{NO}_{3}\right)$ olarak ölçülmüştür. Elde edilen veriler Tablo 4'te verilmiştir.

Yapılan Kruskal Wallis testi sonucunda (Tablo 2); birinci derinlik kademesindeki orman topraklarında başlangıç nitrat mineralizasyonu $\left(\mathrm{T}_{0} \mathrm{NO}_{3}\right)(4,83 \mathrm{~kg} / \mathrm{ha})$ çay topraklarına $(16,6 \mathrm{~kg} / \mathrm{ha})$ göre anlamlı bir şekilde $(p=0,006)$ daha az bulunmuştur (Şekil 4a). Birinci derinlik kademesindeki orman topraklarındaki toplam başlangıç mineralizasyonu $\left(\mathrm{T}_{0} \mathrm{NO}_{3}+\mathrm{NH}_{4}\right)(11,21 \mathrm{~kg} / \mathrm{ha})$ çay $(27,17 \mathrm{~kg} / \mathrm{ha})$ ve findık $(27,31)$ topraklarına göre $\mathrm{p}=0,005$ anlam düzeyinde daha az bulunmuştur (Şekil 4b). İkinci derinlik kademesinde kivi topraklarındaki başlangıç amonyum mineralizasyonu $\left(\mathrm{T}_{0} \mathrm{NH}_{4}\right)(6,91 \mathrm{~kg} / \mathrm{ha})$ fındık topraklarına $(10,9 \mathrm{~kg} / \mathrm{ha})$ göre p<0,001 anlam düzeyinde daha az bulunmuştur (Şekil 4e).

63 günlük mineralizasyon değerleri ile ilgili Kruskal Wallis test sonuçlarına göre (Tablo 2); orman topraklarının birinci derinlik kademesindeki 63 günlük amonyum $\left(\mathrm{T}_{63} \mathrm{NH}_{4}\right)(37,4 \mathrm{~kg} / \mathrm{ha})$ kivi topraklarına $(8,2 \mathrm{~kg} / \mathrm{ha})$ göre $\mathrm{p}=0,001$ önem düzeyinde daha fazla bulunmuştur. Yine kivi topraklarının birinci derinlik kademesindeki 63 günlük mineralizasyon toplamı $\left(\mathrm{T}_{63} \mathrm{NO}_{3}+\mathrm{NH}_{4}\right)(15,4 \mathrm{~kg} / \mathrm{ha})$ orman $(45,4 \mathrm{~kg} / \mathrm{ha})$ ve findik $(69,8 \mathrm{~kg} / \mathrm{ha})$ topraklarına göre sırasıyla $\mathrm{p}=0,005$ ve $\mathrm{p}=0,001$ önem düzeylerinde daha az bulunmuştur (Şekil $4 \mathrm{~d}$ ). Benzer durum ikinci derinlik kademesinde de tespit edilmiştir. Buna göre kivi topraklarındaki $\mathrm{T}_{63} \mathrm{NO}_{3}+\mathrm{NH}_{4}(22,1$ $\mathrm{kg} / \mathrm{ha})$ orman $(55,4 \mathrm{~kg} / \mathrm{ha})$ ve findık $(40,9)$ topraklarına göre sırasıyla $\mathrm{p}=0,007$ ve $\mathrm{p}=0,003$ önem düzeylerinde daha az olarak bulunmuştur (Şekil 4f).

Tablo 4. Toprağa ilişkin azot mineralizasyonunun arazi kullanım durumuna göre karşılaştırılması.

\begin{tabular}{|c|c|c|c|c|c|c|c|c|c|}
\hline & & \multicolumn{4}{|c|}{$0-15 \mathrm{~cm}$} & \multicolumn{4}{|c|}{$15-30 \mathrm{~cm}$} \\
\hline & & Çay & Findık & Kivi & Orman & Çay & Findık & Kivi & Orman \\
\hline \multirow{2}{*}{$\mathrm{T}_{0} \mathrm{NH}_{4}$} & $\overline{\mathbf{x}} \pm \mathbf{S E}$ & $10,0 \pm 0,9$ & $10,9 \pm 0,8$ & $7,6 \pm 0,9$ & $8,4 \pm 1,4$ & $8,6 \pm 0,3$ & $10,8 \pm 0,2$ & $6,6 \pm 0,4$ & $8,0 \pm 2,0$ \\
\hline & $\mathbf{M}$ & $10,4 \mathrm{a}$ & $10,3 \mathrm{a}$ & $7,0 \mathrm{a}$ & $6,78 \mathrm{a}$ & $8,79 \mathrm{ab}$ & $10,9 a$ & $6,91 b$ & $9,87 \mathrm{ab}$ \\
\hline \multirow{2}{*}{$\mathrm{T}_{0} \mathrm{NO}_{3}$} & $\overline{\mathbf{x}} \pm \mathbf{S E}$ & $16,2 \pm 0,2$ & $15,9 \pm 1,9$ & $14,6 \pm 2,8$ & $5,8 \pm 1,0$ & $17,1 \pm 2,3$ & $13,0 \pm 1,9$ & $12,2 \pm 2,6$ & $8,2 \pm 2,1$ \\
\hline & $\mathbf{M}$ & $16,6 \mathrm{a}$ & $15,64 \mathrm{ab}$ & $15,53 \mathrm{ab}$ & $4,83 b$ & $16,07 \mathrm{a}$ & $11,65 \mathrm{a}$ & $10,52 \mathrm{a}$ & $9,56 \mathrm{a}$ \\
\hline \multirow{2}{*}{$\begin{array}{l}\mathrm{T}_{0} \mathrm{NO}_{3} \\
+\mathrm{NH}_{4}\end{array}$} & $\overline{\mathbf{x}} \pm \mathbf{S E}$ & $26,3 \pm 1,2$ & $26,7 \pm 2,4$ & $22,2 \pm 3,3$ & $14,2 \pm 2,4$ & $25,7 \pm 2,4$ & $23,9 \pm 2,1$ & $18,8 \pm 2,8$ & $16,2 \pm 4,1$ \\
\hline & $\mathbf{M}$ & $27,17 \mathrm{a}$ & $27,31 \mathrm{a}$ & $22,54 \mathrm{ab}$ & $11,21 b$ & $23,68 \mathrm{a}$ & $22,66 \mathrm{a}$ & $16,01 \mathrm{a}$ & $19,92 \mathrm{a}$ \\
\hline \multirow{2}{*}{$\mathrm{T}_{63} \mathrm{NH}_{4}$} & $\overline{\mathbf{x}} \pm \mathbf{S E}$ & $20,0 \pm 1,7$ & $33,4 \pm 17,7$ & $8,4 \pm 1,4$ & $42,0 \pm 7,1$ & $14,5 \pm 2,8$ & $18,8 \pm 5,6$ & $11,3 \pm 2,2$ & $36,0 \pm 16,9$ \\
\hline & $\mathbf{M}$ & $18,6 \mathrm{ab}$ & $14,7 \mathrm{ab}$ & $8,2 \mathrm{a}$ & $37,4 b$ & $12,6 \mathrm{a}$ & $13,5 \mathrm{a}$ & $10,4 a$ & $20 a$ \\
\hline \multirow{2}{*}{$\mathrm{T}_{63} \mathrm{NO}_{3}$} & $\overline{\mathbf{x}} \pm \mathbf{S E}$ & $17,9 \pm 8,4$ & $33,7 \pm 14,8$ & $5,9 \pm 1,1$ & $7,1 \pm 1,7$ & $15,8 \pm 3,8$ & $24,6 \pm 3,4$ & $8,7 \pm 3,6$ & $22,3 \pm 11,8$ \\
\hline & $\mathbf{M}$ & $7,4 \mathrm{a}$ & $18 \mathrm{a}$ & $5,6 a$ & $6,0 \mathrm{a}$ & $10,0 \mathrm{a}$ & $26,0 \mathrm{a}$ & $7,6 a$ & $13,3 \mathrm{a}$ \\
\hline \multirow{2}{*}{$\begin{array}{l}\mathrm{T}_{63} \mathrm{NO}_{3} \\
+\mathrm{NH}_{4}\end{array}$} & $\overline{\mathbf{x}} \pm \mathbf{S E}$ & $38,1 \pm 9,6$ & $67,3 \pm 13,6$ & $14,5 \pm 2,0$ & $49,2 \pm 6,7$ & $30,9 \pm 3,4$ & $43,8 \pm 3,8$ & $20,0 \pm 2,6$ & $58,7 \pm 16,3$ \\
\hline & M & $25,7 \mathrm{ab}$ & $69,8 \mathrm{a}$ & $15,4 \mathrm{~b}$ & $45,4 \mathrm{a}$ & $34 \mathrm{ab}$ & $40,9 a$ & $22,1 b$ & $55,4 \mathrm{a}$ \\
\hline
\end{tabular}

* $\overline{\mathrm{X}} \pm \mathrm{SE}$ : Aritmetik ortalama \pm standart hata, M: Medyan

$\mathrm{T}_{0}$ : Başlangıçtaki azot mineralizasyonu, $\mathrm{T}_{63}$ : 63 günlük azot mineralizasyonu

Başlangıç mineralizasyonu değerlerinde orman alanlarının diğer alanlara oranla düşük çıkmasının sebebi tarımsal üretim için diğer alanlarda kimyasal gübrelerin yoğun şekilde kullanımı sonucunda topraktaki azot içeriğinin artması ve bunun alınabilir formda olması ile ilişkilendirilebilir. Çünkü kimyasal gübreler azotun alınabilir formunda toprağa atılırlar. Organik maddenin ayrışması sonucunda açığa çıkan azotun bitkiler tarafından alınabilmesi ancak belirli bir süreç sonucunda olmaktadır (Zhu, 1997).

63 günlük toplam mineralizasyon değerleri bakımından hem birinci hem de ikinci derinlik kademesinde en düşük değerler kivi topraklarında bulunmuştur. 

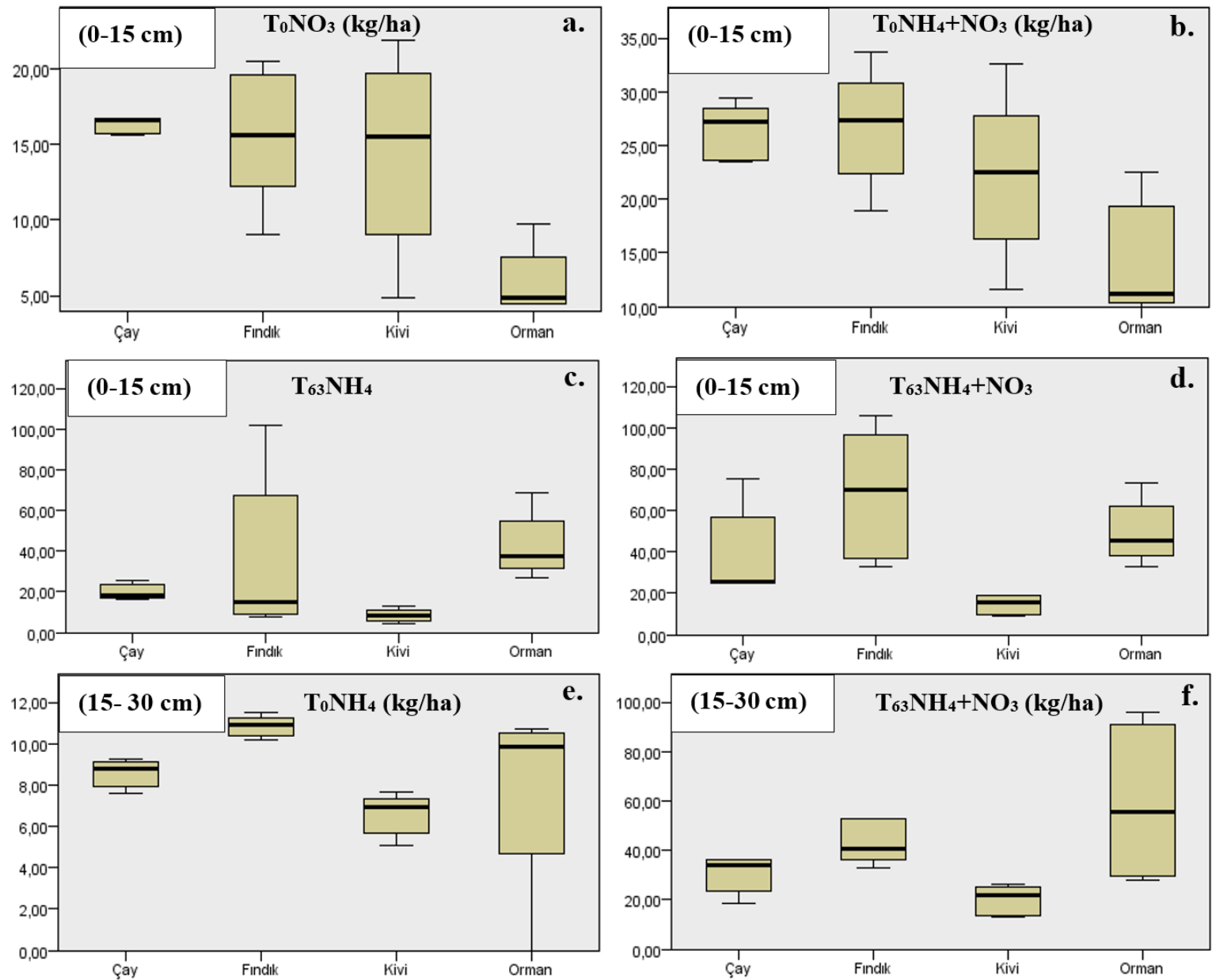

Şekil 4. Arazi kullanım durumuna göre anlamlı farklılık gösteren azot mineralizasyonu değerlerinin değişimi.

Çay topraklarındaki mineralizasyon değerlerinin orman alanlarına göre başlangıçta daha yüksek 63 -günlük değerlerde ise daha yüksek çıkması mineralize olan azotun bir kısmının mikrobiyal olarak tutulduğunu göstermektedir. Orman topraklarındaki 63-günlük amonyum ve toplam mineralizasyonun daha yüksek olması ise daha yüksek organik madde ve daha düşük hacim ağırlığına sahip olması ile açıklanabilir (Wei vd, 2011; Tecimen vd., 2013; Küçük vd., 2019). Bu çalışmada diğer arazi kullanım durumlarına göre ormanlar en yüksek toprak organik madde içeriğine sahiptir (birinci derinlik kademesinde \%8,26, ikinci derinlik kademesinde $\% 6,54)$.

\section{4. Öneriler}

Yapılan bu çalışma ile arazi kullanım durumundaki değişimin toprakların bazı fiziksel ve kimyasal özellikleri ile azot mineralizasyonunu anlamlı bir biçimde etkilediği görülmüştür. Özellikle kum, kil, pH, organik madde, elektriksel iletkenlik, hacim ağırlığı ve başlangıç ve 63 günlük toplam mineralizasyon değerleri arazi kullanım durumuna göre farklılık göstermiştir. Çay fındık ve kivi gibi kültivasyon alanlarındaki yoğun toprak işlemesi ve insan baskısının toprakların organik madde içeriğinde ve başlangıç mineralizasyonu değerlerinde artışa neden olduğu söylenebilir.

Orman alanlarının açılarak yerine ekonomik getirisi daha fazla olan çay, kivi, findık gibi kültivasyon ürünlerinin getirilmesi ile toprak özelliklerinde de önemli birtakım değişiklikler görülmüştür. Kültivasyona başlanmasıyla birlikte toprak tekstürü, $\mathrm{pH}$, organik madde, EC, azot mineralizasyonu gibi toprak kalitesini belirleyen özellikler olumsuz etkilenmektedir. Bu nedenle bu gibi ürünler getirilirken üreticilerin daha dikkatli olması, uygun ve gerektiği kadar gübre kullanması toprağı uygun şekilde işlemesi toprak kalitesinin korunması ve sürdürülebilirlik bakımından daha yararlı olacaktır. 


\section{Kaynaklar}

1. Agnese, C., Bagarello, V., Baiamonte, G., Iovino, M. (2011). Comparing Physical Quality of Forest and Pasture Soils in a Sicilian Watershed. Soil Science Society of America Journal, 75(5), 1958-1970.

2. MGM (2014). Rize İli Meteoroloji İstasyonu Verileri, Meteoroloji Genel Müdürlüğü, Ankara.

3. Assefa, D., Rewald, B., Sanden, H., Rosinger, C., Abiyu, A., Yitaferu, B., Godbold, D. L. (2017). Deforestation and land use strongly effect soil organic carbon and nitrogen stock in Northwest Ethiopia Catena, 153, 89-99.

4. Bahrami, A., Emadodin, I., Atashi, M. R., Bork, H. R. (2010). Land-use change and soil degradation: A case study, North of Iran. Agriculture and Biology Journal of North America, 1, 600-605.

5. Bardak, F. (2016). Farklı Arazi Kullanımının Mikrobiyal Solunum Üzerine Etkisi. Yüksek Lisans Tezi (Yayımlanmamış). AÇÜ, Fen Bilimleri Enstitüsü, Artvin, 56 s.

6. Berendse, F. (1990). Organic matter accumulation and nitrogen mineralization during secondary succession in heathland ecosystems. Journal of Ecology, 78, 413-427.

7. Blake, G. R., Hartge, K. (1986). Bulk Density. In Methods of Soil Analysis: Part 1-Physical and Mineralogical Methods: 363-375.

8. Bouyoucos, G. J. (1962). Hydrometer method improved for making particle size analyses of soils. Agronomy Journal, 54, 464-465.

9. Brady, N. C., Weil, R. R. (2017). The nature and properties of soils. Upper Saddle River: Pearson Prentice Hall, 1104 s.

10. Bremner, J., Keeney D. R. (1965). Steam distillation methods for determination of ammonium, nitrate and nitrite. Analytica Chimica Acta, 32, 485-495.

11. Chakravarty, S., Ghosh, S., Suresh, C., Dey, A., Shukla, G. (2011). Deforestation: Causes, Effects and Control Strategies. In: Global Perspectives on Sustainable Forest Management. Ed. Okia D. C. A., pp. 321.

12. Chen, Q. B., Wang, K. Q., Li, Y. M., Wang, J. Y., Wang, P. L., Da, Q. (2003). Effect of different vegetation types on soil amelioration in dry-hot valley of Jinshajiang River Basin. J. Soil Water Conserv., $17,67-70$.

13. Choromanska, U., De Luca, T. H. (2002). Microbial activity and nitrogen mineralization in forest mineral soils following heating: Evaluationof post-fire effects. Soil Biology and Biochemistry, 34, 263271.

14. Dang, M. V. (2002). Effects of tea cultivation on soil quality in the northern mountainous zone, Vietnam, Doctoral dissertation, University of Saskatchewan, $175 \mathrm{~s}$.

15. Dunn, O. J. (1964). Multiple comparisons using rank sums. Technometrics, 6, 241-252.

16. Elser, J. J., Bracken, M. E. S., Cleland, E. E., Gruner, D. S., Harpole, W. S., Hildebrand, H., Ngai, J. T., Seabloom, E. W., Shurin, J. B., Smith, J. E. (2007). Global analysis of nitrogen and phosphorus limitation of primary producers in freshwater, marine and terrestrial ecosys tems, Ecol. Lett. 10(12), $1135-1142$.

17. Erol, A., Hızal, A. (2006). Gümüşhane İli Köse Deresi Yağış Havzasında Hidro-Fiziksel Toprak Özelliklerinin, Toprak Oluşumunda Etkili Faktörlere Bağlı Olarak Değişimi. Süleyman Demirel Üniversitesi Fen Bilimleri Enstitüsü Dergisi, 10(1), 74-89.

18. Gelaw, A. M., Singh, B. R., Lal, R. (2014). Soil organic carbon and total nitrogen stocks under different land uses in a semi-arid watershed in Tigray, Northern Ethiopia. Agric. Ecosyst. Environ., 188, $256-263$.

19. Germer, S., Neill, C., Krusche, A. V., Elsenbeer, H. (2010). Influence of land-use change on nearsurface hydrological processes: undisturbed forest to pasture. Journal of Hydrology, 380, 473-480.

20. Giardina, P. C., Ryan, M. G., Hubbard, R. M., Binkley, D. (2001). Tree species and soil textural controls on carbon and nitrogen mineralization rates. Soil Science Society of America Journal, 65, 12721279.

21. Göl, C. (2017). Effects of aspect and changes in land use on organic carbon and soil properties in Uludere catchment, semi-arid region: Turkey. Rend Lincei-Sci Fis Nat, 28, 463-469.

22. Gülçur, F. (1974). Toprağın Fiziksel ve Kimyasal Analiz Yöntemleri. İ.Ü. Orman Fakültesi Yayınları, O.F Yayın No, 201, Kurtuluş Matbaası, İstanbul, 225 s.

23. Hall, J. S., Harris, D. J., Medjibe, V., Mark, P., Ashton, S. (2003). The effects of selective logging on forest structure and tree species composition in a Central African forest: implications for management of conservation areas. Forest Ecology and Management, 183, 249-264.

24. Hartemink, A. E., Veldkamp, T., Bai, Z. (2008). Land cover change and soil fertility decline in tropical regions. Turkish Journal of Agriculture and Forestry, 32, 195-213.

25. IBM Corp (2011). IBM SPSS Statistics for Windows, Version 20.0. IBM Corp, Armonk, NY.

26. Islam, K. R., Weil, R. R. (2000). Land use effects on soil quality in a tropical forest ecosystem of Bangladesh. Agric. Ecosyst. Environ., 79, 9-16. 
27. Jackson, R. B., Schenk, H. J., Jobbagy, E. G., Canadell, J., Colello, G. D., Dickinson, R. E., Field, C. B., Friedlingstein, P., Heimann, M., Hibbard, K., Kicklighter, D. W., Kleidon, A., Neilson, R. P., Parton, W. J., Sala, O. E., Sykes, M. T. (2000). Belowground consequences of vegetation change and their treatment in models. Ecol. Appl., 10, 470-483.

28. Kara, Ö., Bolat, İ. (2008). Soil microbial biomass $\mathrm{C}$ and $\mathrm{N}$ changes in relation to forest conversion in the northwestern Turkey. Land Degradation and Development, 19(4), 421-428.

29. Karagül, R. (1999). Trabzon-Söğütlüdere Havzasında Farklı Arazi Kullanım Şekilleri Altındaki Toprakların Bazı Özellikleri ve Erozyon Eğilimlerinin Araştırılması. Türkiye Tarım ve Ormancılık Dergisi, 23, 53-68.

30. Korkanç, S. Y., Özyuvaci, N., Hızal, A. (2008). Impacts of land use conversion on soil properties and soil erodibility. Journal of Environmental Biology, 29, 363-370.

31. Kramer, S., Green, D. M. (2000). Acid and alkaline phosphatase dynamics and their relationship to soil microclimate in a semiarid woodland. Soil Biology and Biochemistry, 32, 179-188.

32. Küçük, M. (2013). Farklı Eğim Ve Bakı Gruplarında Bulunan Meşe Meşcerelerinde Ve Mera Alanlarında Azot Mineralizasyonu Ve Toprak Solunumunun Belirlenmesi. Doktora Tezi (yayımlanmamış). KTÜ, Fen Bilimleri Enstitüsü, Trabzon.193 s.

33. Küçük, M., Yener, İ., Duman, A. (2019). Effects of vegetation cover/land use and slope aspect on surface soll properties near the copper smelter factory in Murgul, Turkey. Applied Ecology And Environmental Research, 17(5), 12305-12321.

34. Lemeneh, M. (2004). Effects of Land Use Changes on Soil Quality and Native Flora Degradation and Restoration in the Highlands of Ethiopia. (Doctoral Thesis). Swedish University of Agricultural Sciences, Uppsala, Sweden.

35. Li, M., Zhu, L. C., Zhang, Q. F., Cheng, X. L (2012). Impacts of different land use types on soil ni trogen mineralization in Danjiangkou Reservoir Area, China, Chin. J. Plant Ecol., 36(6), 530-538.

36. Merilä, P., Strommer, R., Fritze, H. (2002). Soil microbial activity and community structure along a primary succession transect on the land-uplift coast in western Finland. Soil Biology and Biochemistry, 34, 1647-1654.

37. Nelson, R. E. (1982). Carbonate and gypsum. In Methods of Soil Analysis Part 2, 2nd ed. Ed. A.L. pp. 181-197.

38. Oğuz İ., Acar, M. (2011). Tokat Kazova Koşullarında Farklı Arazi Kullanım Türlerinin Bazı Toprak Özellikleri Üzerine Etkisinin Araştırılması. GOÜ, Ziraat Fakültesi Dergisi, 28(2), 171-178.

39. Özalp, M., Yüksel, E. E., Yüksek, T. (2016). Soil Property Changes After Conversion from Forest to Pasture in Mount Sacinka, Artvin, Turkey. Land Degrad. Develop., 27, 1007-1017.

40. Özçağlar, A., Özgür, E. M., Akpınar, N., Somuncu, M., Karadeniz, N., Çabuk, N., Kendir, H., Bayar, R., Yılmaz, M., Yüceşahin, M. M., Yavuz, N. (2006). Rize İli Çamlıhemşin İlçesinde Doğal ve Beşeri Kaynakların Belirlenmesi ve Arazi Kullanım Kararlarının Geliştirilmesi, TÜBİTAK Sosyal ve Beşeri Bilimler Grubu, Proje No: 102K025, Ankara.

41. Pansu, M., Gautheyrou, J. (2007). Handbook of Soil Analysis: Mineralogical, Organic and Inorganic Methods. Springer Berlin Heidelberg, $993 \mathrm{~s}$.

42. Parfitt, R. L., Scott, N. A., Ross, D. J., Salt, G. J., Tate, K. R. (2003). Land-use change effects on soil $\mathrm{C}$ and $\mathrm{N}$ transformations in soils of high $\mathrm{N}$ status: comparisons under indigenous forest, pasture and pine plantation. Biogeochemistry, 66, 203-221.

43. Patel, K., Nirmal Kumar, J. I. N., Kumar, R., Kumar, Bhoi, R. (2010). Seasonal and temporal variation in soil microbial biomass $\mathrm{C}, \mathrm{N}$ and $\mathrm{P}$ in different types land uses of drydeciduous forest ecosystem of Udaipur, Rajasthan, Western India. Applied Ecologyand Environmental Research, 8(4), 377390.

44. Pennock, D., Yates, T., Braidek, J., (2007). Soil sampling designs. In Soil sampling and methods of analysis, pp. 1-14.

45. Ross, D. J., Tate, K. R., Scott, N. A., Felthman, C. W. (1999). Land-use change: effects on soil carbon, nitrogen and phosphorus pools and fluxes in three adjacent ecosystems. Soil Biol Biochem, 31, 803-813.

46. Ross, D. S., Lawrence, G. B., Fredriksen, G. (2004). Mineralization and nitrification patterns at eight northeastern USA forested research sites. Forest Ecology and Management, 188, 317-335.

47. Shi, W., Wang, J. Y., Wei, Y. B., Lv, X. N., Gong, W. (2014). Effects of water and temperature on soil nitrogen mineralization of Cryptomeria fortune plantations in rainy area of West ern China, Chin. J. Soil Sci., 45(6), 1430-1436.

48. Song, Q. N., Yang, Q. P., Yu, D. K., Fang, K., Zhao, G. D., Yu, S. B. (2013). The effects of forest conver sion on soil $\mathrm{N}$ mineralization and its availability in central Jiangxi subtropical region, Acta Ecol. Sin., 33(22), 7309-7318. 
49. Tecimen, H. B. (2011). Orman, Çalı ve Terk Edilmiş Tarla Alanlarındaki Azot Mineralleşmesinin Standart Deneylik Koşullarında İncelenmesi. Journal of the Faculty of Forestry, Istanbul, 61(1), 39-46.

50. Tecimen, H. B., Sevgi, O., Yurtseven, H., Sevgi, E., Öztürk, M. (2013). Net Nitrogen Mineralization and Nitrification Rates in Different Land Uses: An in Situ Incubation - Fresen Environ Bull., 22, 11731178 .

51. Templer, P. H., Groffman, P. M., Flecker, A. S., Power, A. G (2005). Land use change and soil nutrient transformations in the Los Haitises region of the Dominican Republic, Soil Biol. Biochem, 37(2), 215-225.

52. Toohey., R. C., Boll, J., Brooks, E. S., Jones, J. R (2018). Effects of land use on soil properties and hydrological processes at the point, plot, and catchment scale in volcanic soils near Turrialba, Costa Rica. Geoderma, 315, 138-148.

53. URL-1 (2019). http://www-01.ibm.com/support/docview.wss?uid=swg21477370, (21.05.2019).

54. URL-2 (2019)https://www.nrcs.usda.gov/Internet/FSE_DOCUMENTS/nrcs142p2_052803.pdf,

55. (31.10.2019).

56. Walkley, A. (1947). A critical examination of a rapid method for determining organic carbon in soilsEffect of variations in digestion conditions and of inorganic soil constituents. Soil Science, 63, 251-264.

57. Wang, X., Li, M. H., Liu, S., Liu, G. (2006). Fractal characteristics of soils under different land-use patterns in the arid and semiarid regions of the Tibetan Plateau, China. Geoderma, 134, 56-61.

58. Wei, X. R., Shao, M. A., Fu, X. L., Agren, G. I., Yin, X. Q (2011). The effects of land use on soil N mineralization during the growing season on the northern Loess Plateau of China. Geoderma 160, 590598.

59. Wu, J. J., Han, M., Chang, W., Ai, L., Chang, X. X. (2007). The mineralization of soil nitrogen and its influenced factors under alpine meadows in Qilian Mountains, Acta Prataculturae Sin., 16(6), 39-46.

60. Yener, İ., Duman, A., Satıral, C., Avşar, H. (2017). Kızılağaç Meşcerelerinin Çay Bahçelerine Dönüştürülmesi Sonucu Toprakların Bazı Fiziksel ve Kimyasal Özelliklerinde Meydana Gelen Değişimler (Arhavi Örneği). Bartın Orman Fakültesi Dergisi, 19(2), 203-213.

61. Yihenew, G. S., Getachew, A., (2013). Effects of different land use systems on selected physicochemical properties of soils in Northwestern Ethiopia. J. Agric. Sci., 5(4), 112-120.

62. Zhu, Z. L. (1997). Mineralization of soil nitrogen. In Nitrogen in Soils of China. Developments in Plant and Soil Sciences, vol 74. Ed. Zhu, Z., Wen, Q., Freney, J. R. Springer, Dordrecht. 